\title{
PRESENTACIÓN DEL LIBRO «FILOSOFÍA DE LA EDUCACIÓN EN MÉXICO. SELECCIÓN DE PENSADORES, IDEAS E INFLUENCIAS DESDE UNA PERSPECTIVA HISTÓRICA»
}

\section{PHILOSOPHY OF EDUCATION IN MEXICO. SELECTION OF THINKERS, IDEAS, AND INFLUENCES FROM A HISTORICAL PERSPECTIVE}

Cecilia Diego Latin American Philosophy of Education Society (LAPES)

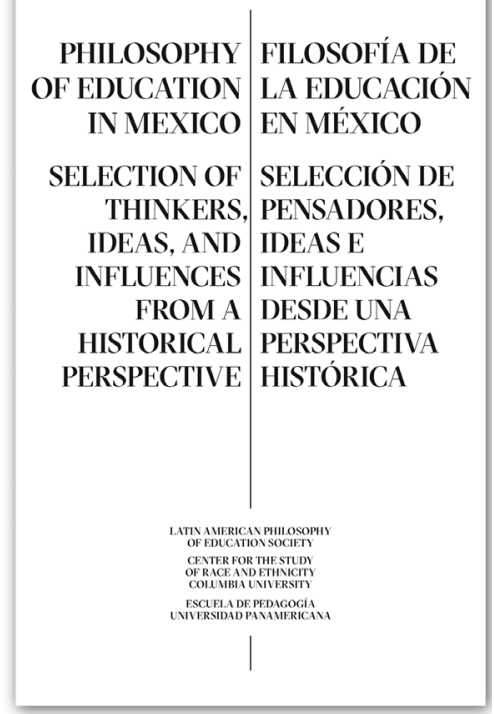

La obra que aquí se presenta comprende siete ensayos, expuestos y ordenados de manera cronológica, acerca de seis importantes personajes -y un séptimo ensayo sobre una problemática educativa- que dejaron su huella en la educación de lo que hoy es el territorio mexicano. Un grupo de seis académicas mexicanas escribieron sobre el tema. Cada una eligió el autor sobre el cual investigaría.

A continuación se presentan, en orden cronológico, los ensayos y sus autoras: 
1. «Nezahualcóyotl. Pensamiento, poesía y educación en México prehispánico». Ana María Valle Vázquez (Centro de Investigación y Docencia en Humanidades del Estado de Morelos-CIDHEM).

2. «El indígena como ser humano en Fray Alonso de la Vera Cruz». María Guadalupe García Casanova (Universidad Nacional Autónoma de México).

3. «La obra educativa de don Vasco de Quiroga en el siglo XVI». Marveya Villalobos Pérez-Cortés (Universidad Panamericana).

4. «Una aproximación a sor Juana Inés de la Cruz: educación femenina en Nueva España». Virginia Aspe Armella (Universidad Panamericana).

5. «Sobre dilemas educativos en el siglo XIX y la controversia para seleccionar los libros de lógica en el currículo». Virginia Aspe Armella (Universidad Panamericana).

6. «José Vasconcelos. Su pedagogía estructurativa, antecedentes e influencia». Ana María del Pilar Martínez Hernández (Universidad Nacional Autónoma de México).

7. «La relación educación y trabajo en el pensamiento de Rafael Ramírez Castañeda». Mónica del Carmen Meza Mejía (Universidad Panamericana).

La creación de esta obra se concibió como un proceso experimental para alimentar la vida académica de autores, editores y lectores. No se buscaba simplemente escribir un libro, sino llevar a cabo una serie de ejercicios mediante los cuales se creara el ambiente propicio para el crecimiento intelectual de la comunidad de aprendizaje, interesada en la filosofía de la educación en Latinoamérica, y sobre todo en México.

Gracias a la participación y apoyo de la Universidad Panamericana (sede Ciudad de México) y al auspicio intelectual y económico de CSER (Center for the Studies of Ethnicity and Race), de la Universidad de Columbia en Nueva York, se lograron espacios de diálogo y debate que enriquecieron esta producción literaria. Durante los primeros seis 
meses del año 2015 se llevaron a cabo varios ejercicios intelectuales cuyo centro temático fueron los ensayos que formarían parte del libro. Entre tales ejercicios encontramos principalmente dos - consecutivos e intrínsecamente ligados- como antecedentes a la sesión de réplicas, evento que originó los textos presentados a continuación, en este número de la revista.

a) Una mesa redonda realizada el 23 de marzo de 2015 en las instalaciones de la Universidad Panamericana (Ciudad de México). Durante este evento, cada autora presentó un resumen de su ensayo en diez minutos y, más tarde, se abrió un espacio para preguntas y respuestas. La mesa redonda fue video-grabada para reproducirse una semana después en un evento realizado en Nueva York.

b) Un taller, elaborado durante el Segundo Simposio Anual que llevó a cabo LAPES en su sede - Columbia University-, donde se proyectó la anterior video-grabación. Ello dio lugar a un diálogo entre los participantes del taller.

El debate que surgió a raíz de ello destaca claramente una realidad fundamental que subyace en todos los proyectos interinstitucionales: la marcada diferencia entre los paradigmas a los que se alinea cada institución. Se quiso aprovechar y catapultar esta realidad como eje central que modificara la metodología, expandiendo - como comunidad intelectual interesada en la filosofía de la educación latinoamericanalos horizontes desde los cuales se vislumbra nuestra historia y nuestro entendimiento de esa historia.

Durante la presentación pregrabada de los ensayos que conforman el libro (en el simposio de LAPES, en Nueva York), surgió una sugerencia que antecede filosóficamente los textos aquí compilados. La sugerencia fue pragmática: incluir, después de cada uno de los ensayos, una breve réplica.

En la siguiente junta con las autoras se les expuso la posibilidad de incluir las réplicas en el libro, aunque ya estaba cerca el final del 
proceso de edición y no se contaba con el espacio suficiente. La conclusión fue creativa: en vez de publicar las réplicas dentro del libro, se realizaría un acto público al que se invitaría a otros académicos para que presentaran una réplica oral. Fue así como se concibió la sesión de réplicas llevada a cabo dentro del Congreso Bianual de la Asociación Latinoamericana de Filosofía de la Educación (ALFE), en la Facultad de Filosofía y Letras de la Universidad Autónoma de México. Cada uno de los siete textos que comprenden el libro fue leído por un académico experto en el tema quien, a su vez, escribió las críticas y los comentarios expuestos en el evento. Los replicantes tardaron setenta minutos en presentar sus escritos, dejando tiempo para que, si lo deseaban, las autoras pudieran contestar y, finalmente, se abrió un espacio para que el público pudiera realizar sus cuestionamientos. A continuación se presentan los nombres de los expertos que realizaron las réplicas de los ensayos del libro, por orden cronológico:

1. Rodolfo Cisneros Contreras (Universidad Nacional Autónoma de México).- «Nezahualcóyotl. Pensamiento, poesía y educación en México Prehispánico», de Ana María Valle Vázquez.

2. Renato Huarte Cuéllar (Universidad Nacional Autónoma de México).- «El indígena como ser humano en fray Alonso de la Vera Cruz», de María Guadalupe García Casanova.

3. Luis Aarón Patiño Palafox (Universidad Nacional Autónoma de México y Universidad Panamericana).- «La obra educativa de don Vasco de Quiroga en el siglo XVI», de Marveya Villalobos Pérez-Cortés.

4. Robin Ann Rice (Universidad Popular Autónoma del Estado de Puebla).- «Una aproximación a sor Juana Inés de la Cruz: educación femenina en Nueva España», de Virginia Aspe Armella.

5. José Luis Rivera Noriega (Universidad Panamericana).- «Sobre dilemas educativos en el siglo XIX y la controversia para seleccionar los libros de lógica en el currículo», de Virginia Aspe Armella. 
6. Hilda Patiño Domínguez (Universidad Iberoamericana).- «José Vasconcelos. Su pedagogía estructurativa, antecedentes e influencia», de Ana María del Pilar Martínez Hernández.

7. María del Pilar Baptista Lucio (Universidad Panamericana).- «La relación educación y trabajo en el pensamiento de Rafael Ramírez Castañeda», de Mónica del Carmen Meza Mejía. 